\title{
Anabases
}

ANABASES Traditions et réceptions de l'Antiquité

$14 \mid 2011$

Varia

\section{Claudio schIANo, Artemidoro di Efeso e la scienza del suo tempo}

\section{Germaine Aujac}

\section{OpenEdition}

\section{Journals}

Édition électronique

URL : http://journals.openedition.org/anabases/2853

DOI : 10.4000/anabases. 2853

ISSN : 2256-9421

\section{Éditeur}

E.R.A.S.M.E.

\section{Édition imprimée}

Date de publication : 1 octobre 2011

Pagination : 292-293

ISSN : 1774-4296

\section{Référence électronique}

Germaine Aujac, "Claudio schiano, Artemidoro di Efeso e la scienza del suo tempo », Anabases [En ligne], 14 | 2011, mis en ligne le 01 octobre 2011, consulté le 22 septembre 2020. URL : http:// journals.openedition.org/anabases/2853; DOI : https://doi.org/10.4000/anabases.2853

Ce document a été généré automatiquement le 22 septembre 2020.

(c) Anabases 


\title{
Claudio schiano, Artemidoro di Efeso e la scienza del suo tempo
}

\author{
Germaine Aujac
}

\section{RÉFÉRENCE}

Claudio schiano, Artemidoro di Efeso e la scienza del suo tempo, Bari, Edizioni Dedalo, 2010, $192 \mathrm{p}$.

20 euros / ISBN 978-88-220-5816-4.

1 Le mystérieux papyrus exposé à Turin a provoqué un regain d'intérêt pour Artémidore d'Éphèse, auteur, au $\mathrm{I}^{\mathrm{er}}$ siècle avant notre ère, d'une Géographie en onze livres que nous ne connaissons guère que par ce qu'en ont dit ses successeurs, Strabon surtout, puis Étienne de Byzance. L'attribution à Artémidore des quatre colonnes que l'on peut lire sur le papyrus et dans lesquelles on a cru voir une description de l'Espagne méridionale a provoqué bien des controverses et suscité des travaux variés, au nombre desquels il faut compter l'ouvrage de Claudio Schiano dont l'un des objectifs est de mettre en doute l'authenticité de ce papyrus. Le premier chapitre (p. 9-34) examine la dette de Strabon envers Artémidore, qu'il connaît surtout par l'intermédiaire de Posidonius. Vers 400 de notre ère, Marcianus d'Héraclée aurait composé, outre un Périple de la mer Extérieure, conservé en partie, un Abrégé du Périple d'Artémidore, dont il ne reste que les parties relatives aux côtes méridionales de la mer Noire.

Le second chapitre (p. 35-92) pose la question de la division en livres de la Géographie d'Artémidore : peut-on y répondre avec quelque certitude ? Comparant les mesures du monde données par Ératosthène et Artémidore, l'A. fait la distinction, valable en soi, entre le monde-globe terrestre et le monde habité ; mais il est regrettable qu'il parle de "planète ", un terme bien anachronique, et qu'il utilise directement des mesures modernes, en degrés et minutes, inconnues à l'époque.

Le troisième et dernier chapitre (p. 93-139) rappelle les différents itinéraires, présentés par divers auteurs, concernant l'Espagne méridionale. L’A. conclut que le papyrus, loin 
d'être l'écho direct de l'œuvre d'Artémidore, n'est qu'un succédané de l'abrégé de Marcianus.

Un important appendice (p. 141-156) réunit dix-neuf fragments que l'A. range dans le livre I de la Géographie d'Artémidore. Pline, Agathémère, Strabon, Étienne de Byzance, Marcianus d'Héraclée livrent ainsi le peu que l'on puisse légitimement attribuer à cet auteur qui connait depuis peu une vogue inattendue.

5 Une abondante bibliographie (p.157--169), un index des noms antiques et modernes (p. 171-175) suivi par un index des noms géographiques (p. 176-180), un index des passages cités (p.181-188), un index des planches (p.189) donnent au lecteur toutes facilités pour faire bon usage de cette savante mise au point.

\section{AUTEURS}

\section{GERMAINE AUJAC}

Université de Toulouse (UTM)

aujac.germaine@wanadoo.fr 